\title{
Biochemical Alterations in Zinc Deficient Sheep Associated by Hyperlactatemia
}

\begin{abstract}
Ali Hafez El-Far
Department of Biochemistry, Faculty of Veterinary Medicine, Damanhour University, Egypt

Received 2013-06-25, Revised 2013-07-04; Accepted 2013-07-25

ABSTRACT

Blood samples from diseased and clinically healthy Balady sheep of both sexes were collected and subjected for biochemical analysis of serum glucose, fructosamine, lactate, growth hormone, insulin, creatine phosphokinase, Lactate dehydrogenase and aldolase. The obtained results revealed a significant decrease in serum zinc and growth hormone were stated. In contrary, serum glucose and lactate, insulin, CPK, LDH and aldolase were significantly increased statically. While, fructosamine levels were non-significantly increased. From these results can conclude that, in zinc deficient sheep the carbohydrate metabolism is directed toward the anaerobic one accompanied by hyperlactemia which induce muscle cramp and damages leading to increased CPK, LDH and aldolase which appear clinically as enlargement of knee joint, lameness and staggering gait. In addition, growth retardation and wool loss are the main clinical signs of reduction in growth hormone.
\end{abstract}

Keywords: Hypozincemia, Anaerobic Metabolism, Hyperlactatemia Growth Retardation

\section{INTRODUCTION}

Trace elements are very essential to lots of biomolecules such as hormones and enzymes. So, they should be incorporated in the food of human being and animals (Dillitzer et al., 2011). Zinc is one of those important elements which considered a component of hundreds of enzymes and is involved in the synthesis, storage and release of insulin (Miao et al., 2013). Moreover, it is essential for other hormones such as GH, thyroid stimulating hormone, Luteinizing hormone, follicular stimulating hormone and adrenocorticotrophic hormone (Alves et al., 2012). Zinc an intracellular cation, is required to serve either a catalytic or structural role of many enzymes in mammals (Jeong et al., 2012). Zinc-containing enzymes participate in many components of metabolism and cell replication. In addition, some zinc-containing enzymes, such as carbonic anhydrase and lactate dehydrogenase, are involved in intermediary metabolism during exercise. Another zinc-containing enzyme, superoxide dismutase, protects against free radical damage (Kavas et al., 2013). Zinc deficiency might be explained by the lack of key enzymes required for carbohydrate metabolism because of reduced expression of zinc dependent messenger RNA needed to synthesize these enzymes (Li et al., 2013). So, zinc deficiency conveys the carbohydrate metabolism to word the anaerobic metabolism.

Zinc deficiency might be reduced animal's appetite by impairing the taste which depends on salivary zinc dependent polypeptide (Suzuki et al., 2011). The reduced appetite in zinc deficient animals could be the reason for the paleness of mucous membranes, depression of growth rate and the lowered body weight (Al-Saad et al., 2010). In the same context, zinc is crucial for normal development and function of neutrophils and natural killer cells. Moreover, zinc is important for gene regulation within the lymphocytes, T-cell activation, T-helper 1 and cytokine production, growth, reproduction, development, differentiation, antioxidant functions, gene expression, DNA synthesis, 
neurotransmitters and apoptosis (Fouda et al., 2011). Clinically, zinc deficiency is associated with parakeratosis, growth retardation, wrinkled skin, wool loss, swollen hocks, excessive salivation, alopecia, scaling and crusting of the skin of the face, neck and distal extremities (Al-Saad et al., 2010).

Our study aimed to investigate the biochemical effects of zinc deficiency in lambs on carbohydrate metabolism and growth throughout the biochemical analysis of serum glucose, fructosamine, lactate, Growth Hormone (GH), insulin, Creatine Phosphokinase (CPK; EC 2.7.3.2), lactate dehydrogenase (LDH; EC 1.1.1.27) and aldolase (EC; 4.1.2.13).

\section{MATERIALS AND METHODS}

\subsection{Animals and Experimental Design}

The present investigation was carried out on twenty diseased Balady sheep (4-5 years old) of both sexes from a flock of sheep at Al-Beheira Governorate, Damanhour city. Another twenty clinically healthy Balady sheep related to another flock at the same locality fed on balanced concentrate mixture and roughage were served as a control group.

\subsection{Blood Samples}

The blood samples were collected from the jugular vein by using a sterile sharp needle with wide pore. Serum samples were collected in dry clean tubes and separated by centrifugation at 3000 RPM for 10 min then clear serum supernatantswere aspirated carefully and subjected to biochemical analysis.

\subsection{Biochemical Analysis}

Collected serum samples were subjected to biochemical analysis of zinc, glucose, fructosamine, lactate, insulin, $\mathrm{GH}, \mathrm{CPK}, \mathrm{LDH}$ and aldolase. All biochemical parameters were analyzed by commercially available kit methods.

\subsection{Statistical Analysis}

The descriptive data are presented as the means \pm SE. The statistical differences were calculated based on two way test of ANOVA and $\mathrm{p}<0.05$ is considered as significant between the groups.

\section{RESULTS}

The data illustrated in the diseased group in comparison to control one recorded a significant $(p<0.05)$ decrease in the levels of serum zinc. While, the levels of serum glucose and lactate were statistically significantly increased. In regard to the fructosamine levels were increased but non-significantly. The effect of hypozincemia in diseased sheepwas significantly decreased the levels of GH. In contrary, serum insulin levels were significantly increased in contribution to control one (Table 1).

The data presented in Table 2 stated a significant $(p<0.05)$ increase in the enzyme activities of CPK, LDH and aldolase in the diseased group in comparison to control one.

\section{DISCUSSION}

Careful clinical examination of diseased sheep revealed the presence of alopecia at the neck, shoulder and abdomen, easily detached wool and rough wool. Also, there was an enlargement of the knee joint. Additional signs include anorexia, depression, poor growth, pale mucous membrane, lameness, staggering gait and diarrhea were observed in zinc deficient sheep than in the apparently healthy. While, the mechanism of poor wool growths observed in hypozincemia perhaps involving impaired protein synthesis (Al-Saad et al., 2010). Moreover, parakeratosis might be attributed to the importance of zinc as an activator of some enzymes contributed in carbohydrate, lipids, protein and nucleic acid metabolism (Yasuda et al., 2011; Alves et al., 2012).

Table 1. Mean values of zinc (ug/dl), fructosamine ( $\mathrm{mmol} / \mathrm{L})$, glucose (mg/dl), lactate (mg/dl), insulin (ng/ml) and $\mathrm{GH}(\mathrm{ng} / \mathrm{ml})$ in control and diseased groups

\begin{tabular}{|c|c|c|c|c|c|c|}
\hline & Zinc & Glucose & Fructosamine & Lactate & Insulin & GH \\
\hline Control group & $70.74 \pm 2.37^{\mathrm{a}}$ & $42.36 \pm 0.89^{b}$ & $2.00 \pm 0.14^{\mathrm{a}}$ & $10.23 \pm 0.64^{b}$ & $11.72 \pm 1.80^{b}$ & $1.46 \pm 0.24^{\mathrm{a}}$ \\
\hline Diseased group & $44.13 \pm 3.16^{\mathrm{b}}$ & $72.19 \pm 4.17^{\mathrm{a}}$ & $3.35 \pm 0.63^{\mathrm{a}}$ & $160.54 \pm 21.46^{\mathrm{a}}$ & $28.62 \pm 3.34^{\mathrm{a}}$ & $0.08 \pm 0.01^{\mathrm{b}}$ \\
\hline
\end{tabular}

Values are mean \pm standard error of mean; Means within the same column carrying different letters are significantly different $(\mathrm{p}<0.05)$

Table 2. Mean values of LDH (U/L), CPK (U/L) and aldolase (U/L) in control and diseased groups

\begin{tabular}{lccc}
\hline & LDH & CPK & Aldolase \\
\hline Control group & $349.00 \pm 7.59^{\mathrm{b}}$ & $148.16 \pm 5.43^{\mathrm{b}}$ & $2.59 \pm 0.26^{\mathrm{b}}$ \\
Diseased group & $2165.30 \pm 9.58^{\mathrm{a}}$ & $314.00 \pm 11.53^{\mathrm{a}}$ & $13.23 \pm 2.01^{\mathrm{a}}$ \\
\hline
\end{tabular}

Values are mean \pm standard error of mean; Means within the same column carrying different letters are significantly different $(\mathrm{p}<0.05)$ 
The mechanism of alopecia in zinc deficient animal might be contributed to the reduction of the follicular epithelium capacity to produce a fiber (Finner, 2013). Alopecia was the most frequent sign in sheep with zinc deficiency. This finding is in accordance with those of others and buffalo calves (Al-Saad et al., 2010).

The effects of zinc deficiency on carbohydrate metabolism in zinc deficient sheep were illustrated in Table (1 and 2) which represented by a significant increase in serum glucose concentrations. The same findings were reported in zinc deficient pups (Jou et al., 2010) and diabetic rats (Fatmi et al., 2013). The hyperglycemia associated with hypozincemia is associated with hyperinsulinemia as reported by (Suzuki et al., 2011; Marreiro et al., 2006; Jansen et al., 2012). Hyperglycemia and hyperinsulinemia in zinc deficient lambs could be evidence that zinc deficiency decreased the insulin uptake. In the same manner, the plasma glucose of the zinc deficient group was significantly higher than control one. On the contrary, liver glycogen of the zinc deficient animals was significantly lower (Miao et al., 2013).

The prolonged hyperglycemia in zinc deficient lambs were increased the glycosylated protein as fructosamine which formed due to a non-enzymatic Amadori rearrangement between glucose and amino acid residues of proteins. So, fructosamine is a medium term indicator of 2-3 weeks of hyperglycemia (Chon et al., 2013). Fructosamine is also formed when the carbonyl group of glucose reacts with an amino group of a serum albumin, as the double bond to oxygen moves from the end carbon atom to the next carbon atom with the production of water (Lee et al., 2013a).

In hypozincemia, hyperglycemia and hyperinsulinemia are the strict evidence of that, the carbohydrate metabolism was conveyed toward the anaerobic which produce lactate as an end product of catabolism. Plasma lactate levels in zinc deficient animals were significantly higher than those in control one (Myers et al., 2012). The blood lactate concentration reflects a balance between production and uptake of lactate in tissues. Lactate is formed by reduction of pyruvate and is metabolized by oxidation to pyruvate in the reaction catalyzed by the cytosolic NAD-dependent lactate dehydrogenase (Ballas, 2013). The metabolic fate of pyruvate is mainly mitochondrial oxidation to carbon dioxide and water with accompanying energy production in the respiratory chain. The latter sequence of reactions is oxygen requiring and with insufficient oxygen supply, or if pyruvate production for other reasons exceeds the capacity of oxidative metabolism, pyruvate will be diverted to lactate (Kruse et al., 2011). In this situation, impaired cellular respiration leads to lower $\mathrm{pH}$ levels. Simultaneously, cells are forced to metabolize glucose anaerobically, which leads to lactate formation. Therefore, elevated lactate is indicative of tissue hypoxia, hypoperfusion and possible damage (Volpato et al., 2012). The increment of lactic acid is evidenced by the duplication of LDH enzyme activities in zinc deficient lambs. Meanwhile, $\mathrm{LDH}$ is an essential enzyme involved in anaerobic glycolysis and is responsible for the anaerobic transformation of pyruvate to lactate (Neal et al., 2013). The significant increase in LDH indicates the damage of the muscles either cardiac or striated muscle as LDH increases were accompanied by a significant increase in CPK which clinically are assayed as a marker of myocardial infarction, severe muscle breakdown andmuscular damage (Tsitsimpikou et al., 2013). A serum CPK activity is an indicator commonly used in the diagnosis of heart and skeletal muscle disorders (Baird et al., 2012). In muscle damage, CPK levels have been increased. Such levels clearly signal strong disturbance or disintegration of striated muscle tissue with concomitant leakage of intracellular muscle constituents into the circulation (Iwasa et al., 2013). Furthermore, the incidence of skeletal muscle injury is increasingly more prevalent in the preclinical evaluation of new therapeutic monitored by commonly used serological biomarkers, including CPK and aldolase (Toledano et al., 2012). In addition to a significant increase in serum LDH and CPK activities a sensitive marker of myopathy aldolase was significantly increased in zinc deficient sheep. The elevated serum aldolase is associated with syndromes including myopathies with discomfort and weakness, systemic disorders and myopathology in perimysial connective tissue (Nozaki and Pestronk, 2009). Moreover, the damage of muscle tissue can be defined as the disruption of plasma membrane accompanied by the loss of muscle proteins as CPK, myoglobin, LDH, aldolase and troponin (Tsitsimpikou et al., 2013). The damage in muscle fibers is a result of anaerobic metabolic pathway with accumulation of lactate which lead to muscle cramp and damage of some muscle fibers which observed clinically by enlargement of knee joint, lameness and staggering gait.

The obtained results indicated a significant decrease in growth hormone level which consequently, retards the growth of zinc deficient animal. Previous research has shown that a severe zinc deficiency can 
result in impaired growth in lambs (Al-Saad et al., 2010). Zinc is required for the stabilization of the DNA and RNA. In fact, all RNA polymerases (I, II, III) are zinc metalloenzymes (Lee et al., 2013b). So, zinc is an essential nutrient and plays an important role in the growth. Concomitantly, zinc deficiency has been known to cause growth retardation along with a drastic decrease in GH production and/or Insulin-like Growth Factor-I (IGF-I) (Hamza et al., 2012). One likely partial explanation for the growth restriction seen in zinc deficiency is the suppression of IGF-1 which the essential molecule for growth hormone physiology (Jayawardena et al., 2012).

\section{CONCLUSION}

From the obtained data we can conclude that, zinc deficiencyin sheep leads to hyperglycemia and hyperinsulinemia which directs the carbohydrate metabolism toward the anaerobic process which pronounced by a drastic increase in lactate which consequently accumulated in in the muscles leading to muscle cramp and damages which monitored by a significant elevation of serum LDH, CPK and aldolase. Moreover, growth retardation was recorded as a result of a reduction in growth hormone.

\section{REFERENCES}

Al-Saad, K.M., H.I. Al-Sadi and M.O. Abdul-Majeed 2010. Clinical, hematological, biochemical and pathological studies on zinc deficiency (Hypozincemia) in sheep. Vet. Res., 3: 14-20. DOI: 10.3923/vr.2010.14.20

Alves, C.X., S.H. Vale, M.M. Dantas, A.A. Maia and M.C. Franca et al., 2012. Positive effects of zinc supplementation on growth, GH, IGF1 and IGFBP3 in eutrophic children. J. Pediatr. Endocrinol. Metab., 25: 881-887. DOI: 10.1515/jpem-2012-0120

Baird, M.F., S.M. Graham, J.S. Baker and G.F. Bickerstaff, 2012. Creatine-kinase- and exerciserelated muscle damage implications for muscle performance and recovery. J. Nutr. Metab., 2011: 960363-960375. DOI: 10.1155/2012/960363

Ballas, S.K., 2013. Lactate dehydrogenase and hemolysis in sickle cell disease. Blood, 121: 243-244. PMID: 23287628

Chon, S, Y.J. Lee, G. Fraterrigo, P. Pozzilli and M.C. Choi et al., 2013. Evaluation of glycemic variability in well-controlled type 2 diabetes mellitus. Diabetes Technol. Ther., 15: 455-460. PMID: 23617251
Dillitzer, N., N. Becker and E. Kienzle, 2011. Intake of minerals, trace elements and vitamins in bone and raw food rations in adult dogs. Br. J. Nutr., 106: S53-S56. PMID: 22005436

Fatmi, W., Z. Kechrid, M. Nazıroglu and M. FloresArce, 2013. Selenium supplementation modulates zinc levels and antioxidant values in blood and tissues of diabetic rats fed zinc-deficient diet. Biol. Trace. Elem. Res., 152: 243-250. DOI: 10.1007/s12011-013-9613-z

Finner, AM., 2013. Nutrition and hair: Deficiencies and supplements. Dermatol. Clin., 31: 167-172. PMID: 23159185

Fouda, T.A., M.A. Youssef and W.M. El-Deeb, 2011. Correlation between zinc deficiency and immune status of sheep. Vet. Res., 4: 50-55. DOI: 10.3923/vr.2011.50.55

Hamza, R.T., A.I. Hamed and M.T. Sallam, 2012. Effect of zinc supplementation on growth hormone-insulin growth factor axis in short Egyptian children with zinc deficiency. Ital. J. Pediatr., 38: 21-21. PMID: 22625223

Iwasa, M., W. Aoi, K. Mune, H. Yamauchi and K. Furuta et al., 2013. Fermented milk improves glucose metabolism in exercise-induced muscle damage in young healthy men. Nutr. J., 12: 8383. DOI: $10.1186 / 1475-2891-12-83$

Jansen, J, E. Rosenkranz, S. Overbeck, S. Warmuth and E. Mocchegiani et al., 2012. Disturbed zinc homeostasis in diabetic patients by in vitro and in vivo analysis of insulinomimetic activity of zinc. J. Nutr. Biochem., 23: 1458-1466. DOI: 10.1016/j.jnutbio.2011.09.008

Jayawardena, R., P. Ranasinghe, P. Galappatthy, R.L. Malkanthi and G.R. Constantine et al., 2012. Effects of zinc supplementation on diabetes mellitus: A systematic review and meta-analysis. Diabetol. Metab. Syndrome, 4: 13-13. PMID: 22515411

Jeong, J., J.M. Walker, F. Wang, G.J. Park and A.E. Palmer et al., 2012. Promotion of vesicular zinc efflux by ZIP13 and its implications for spondylocheiro dysplastic ehlers-danlos syndrome. PNAS, 109: E3530-E3538. DOI: 10.1073/pnas. 1211775110

Jou, M.Y., A.F. Philipps and B. Lonnerdal, 2010. Maternal zinc deficiency in rats affects growth and glucose metabolism in the offspring by inducing insulin resistance postnatally. J. Nutr., 140: 16211627. DOI: $10.3945 /$ jn. 109.119677 
Kavas, G.O., P.A. Ayral and A.H. Elhan, 2013. The effects of resveratrol on oxidant/antioxidant systems and their cofactors in rats. Adv. Clin. Exp. Med., 22: 151-155. PMID: 23709370

Kruse, O., N. Grunnet and C. Barfod, 2011. Blood lactate as a predictor for in-hospital mortality in patients admitted acutely to hospital: A systematic review. Scandinavian J. Trauma, Resuscit. Emergency Med., 19: 74-74. DOI: 10.1186/17577241-19-74

Lee, S.Y., Y.C. Chen, I.C. Tsai, C.J. Yen and S.N. Chueh et al., 2013a. Glycosylated hemoglobin and albumin-corrected fructosamine are good indicators for glycemic control in peritoneal dialysis patients. PLoS ONE, 8: e57762. DOI: 10.1371/journal.pone.0057762

Lee, Y.J., C.Y. Lee, A. Grzechnik, F. Gonzales-Zubiate and A.A. Vashisht et al., 2013b. RNA polymerase I stability couples cellular growth to metal availability. Mol. Cell, 51: 105-115. DOI: 10.1016/j.molcel.2013.05.005

Li, X., Y. Guan, X. Shi, H. Ding and Y. Song et al., 2013. Effects of high zinc levels on the lipid synthesis in rat hepatocytes. Biol. Trace Elem. Res., 154: 97-102. PMID: 23695729

Marreiro, D.D.N., B. Geloneze, M.A. Tambascia, A.C. Lerario and A. Halpern et al., 2006. Effect of zinc supplementation on serum leptin levels and insulin resistance of obese women. Biol. Trace Elem. Res., 112: 109-118. DOI: 10.1385/BTER:112:2:109

Miao, X., W. Sun, Y. Fu, L. Miao and L. Cai, 2013. Zinc homeostasis in the metabolic syndrome and diabetes. Front Med., 7: 31-52. DOI: 10.1007/s1 1684-013-0251-9. PMID: 23385610

Myers, S.A., A. Nield and M. Myers, 2012. Zinc transporters, mechanisms of action and therapeutic utility: Implications for type 2 diabetes mellitus. J. Nutr. Metab., 2012: 173712-173724. DOI: $10.1155 / 2012 / 173712$
Neal, J.L., N.K. Lowe and E.J. Corwin, 2013. Serum lactate dehydrogenase profile as a retrospective indicator of uterine preparedness for labor: A prospective, observational study. BMC Pregnancy Childbirth, 13: 128-128. DOI: 10.1186/1471-239313-128

Nozaki, K. and A. Pestronk, 2009. High aldolase with normal creatine kinase in serum predicts a myopathy with perimysial pathology. J. Neurol. Neurosurg Psychiatry, 80: 904-908. DOI: 10.1136/jnnp.2008, PMID: 19240048

Suzuki, H., A. Asakawa, J.B. Li, M. Tsai and H. Amitani et al., 2011. Zinc as an appetite stimulator-the possible role of zinc in the progression of diseases such as cachexia and sarcopenia. Recent Pat. Food Nutr. Agric., 3: 226-231. PMID: 21846317

Toledano, C., M. Gain, A. Kettaneh, B. Baudin and C. Johanet et al., 2012. Aldolase predicts subsequent myopathy occurrence in systemic sclerosis. Arthritis Res. Therapy, 14: R152-R152. DOI: 10.1186/ar3888

Tsitsimpikou, C., N. Kioukia-Fougia, K Tsarouhas, P. Stamatopoulos and E. Rentoukas et al., 2013. Administration of tomato juice ameliorates lactate dehydrogenase and creatinine kinase responses to anaerobic training. Food Chem. Toxicol., S02786915: 00896-00900. PMID: 23291317

Volpato, R., L. Rodello, R.B. Abibe, M.D. Lopes, 2012. Lactate in bitches with pyometra. Reprod Domest. Anim., 47: 335-336. PMID: 23279532

Yasuda, H., K. Yoshida, Y. Yasuda and T. Tsutsui, 2011. Infantile zinc deficiency: Association with autism spectrum disorders. Sci. Rep., 129: 1-5. DOI: $10.1038 /$ srep00129 